BULLETIN Bulletin hispanique

HISPANIQUE Université Michel de Montaigne Bordeaux

$115-2$ | 2013

Les traductions vieillissent-elles ?

\title{
Oswaldo Holguín Callo, Cafés y fondas en Lima ilustrada y romántica
}

Isabelle Tauzin-Castellanos

\section{(2) OpenEdition}

1 Journals

\section{Edición electrónica}

URL: http://journals.openedition.org/bulletinhispanique/2946

DOI: 10.4000/bulletinhispanique.2946

ISSN: 1775-3821

\section{Editor}

Presses universitaires de Bordeaux

\section{Edición impresa}

Fecha de publicación: 28 diciembre 2013

Paginación: 781-783

ISBN: 978-2-86781-908-7

ISSN: 0007-4640

\section{Referencia electrónica}

Isabelle Tauzin-Castellanos, « Oswaldo Holguín Callo, Cafés y fondas en Lima ilustrada y romántica », Bulletin hispanique [En línea], 115-2 | 2013, Publicado el 14 febrero 2014, consultado el 23 septiembre 2020. URL : http://journals.openedition.org/bulletinhispanique/2946 ; DOI : https://doi.org/10.4000/ bulletinhispanique.2946

Este documento fue generado automáticamente el 23 septiembre 2020.

Tous droits réservés 


\title{
Oswaldo Holguín Callo, Cafés y fondas en Lima ilustrada y romántica
}

\author{
Isabelle Tauzin-Castellanos
}

\section{REFERENCIA}

Oswaldo Holguín Callo, Cafés y fondas en Lima ilustrada y romántica. Lima, USMP, 2013, 242 p. ISBN : $612408872 \mathrm{X}, 9786124088728$

1 El libro de Oswaldo Holguín nos brinda una imagen de la Lima perdida, aquella Lima de los espacios de sociabilidad que fueron cafés y fondas a finales del virreinato y antes del cataclismo de la guerra del Pacífico.

2 No se trata de un libro nostálgico aunque es la continuación de un artículo publicado por el mismo autor sobre el Café de Bodegones en 1998, cuando el Perú no se había convertido aún en cuna de chefs de renombre internacional. Nos desvela el mundo de los hospedajes de la capital, como por ejemplo la célebre fonda de la Bola de Oro, que no pudo soportar la competencia de los modernos hoteles.

3 La investigación se ubica a medio camino entre la historia social y la historia cultural, y se basa en fuentes tan variadas como la Memoria de gobierno del virrey Amat, las estadísticas de Córdova y Urrutia, los relatos de viajeros desde Heinrich Witt hasta Middendorf y Lastarria. En la lista destacan Ricardo Palma que es un informante excelso ya que las tradiciones no son pura ficción y el liberal Fernando Casós, otro testigo de valía en tanto autor de la novela realista Los amigos de Elena. Unos dibujos de Ignacio Merino sacados de la edición parisina de Lima por dentro y por fuera (1854) grafican la reconstrucción de la historia cotidiana.

4 Oswaldo Holguín completa su exploración apasionante con el auxilio de las sucesivas ediciones del Diccionario de la Real Academia ; demuestra la gran variedad lingüística anterior a la invasión de los anglicismos 'hotel', 'confort' y 'turista'.

5 Así fue como los primeros Cafés limeños competían con bodegones, mesas redondas, cocinerías y alojerías. La aloja, bebida dulce y aromatizada muy popular, y el chocolate 
de añeja tradición se vieron relegados por el café, bebida exótica, importada, que permitía trasladar al Perú la moda europea, símbolo de elegancia e ilustración.

6 Los primeros establecimientos de la América Meridional abrieron en Lima y fueron espacios dedicados a la charla y al juego, con mesas autorizadas de billar y truco, y otras clandestinas para los dados. En 1791 había 6 cafés en Lima ; en 1876 ascendían a 34 y competían con la nueva moda de los clubes. El café emblemático fue el de Bodegones, primero llamado del Comercio y recordado por el joven Palma como de los Viejos, frecuentado por parroquianos tan especiales como el latinista empedernido Basilio Yeguas.

7 La influencia francesa fue más notable en el auge de las fondas que proporcionaban a la vez comidas, bebidas y alojamiento. El primer ensayo de hospedaje moderno, según $\mathrm{O}$. Holguín, fue el Café de Santo Domingo que ofreció a partir de 1819 habitaciones individuales a los forasteros recelosos de los populares tambos ubicados en las afueras de la ciudad. Flora Tristán cuenta su estadía en casa de la francesa Denuelle, desde donde llega a observar el trajín limeño.

La fonda de La Bola de Oro, con un nombre muy frecuente en Francia y que se explica tal vez por una linterna en la entrada, reemplazó el café de Mercaderes en 1837 y fue regentada durante treinta años por Joseph Cier, tipo del migrante francés emprendedor. Llegó a emplear unos 50 mozos oriundos de Huaylas y Conchucos para el servicio de un inmenso comedor. La segunda planta estaba habilitada con 50 apartamentos para huéspedes y se alquilaban 30 habitaciones a prostitutas; entre ambas secciones un espacio se reservaba a las cartas y otro cuarto al juego prohibido de los dados.

El éxito fomenta la envidia. Cier fue atacado en una serie de comunicados publicados por El Comercio. Se enfrentó a la competencia de otros franceses, dueños del Hotel de Baños Tibios o de Morin, más cómodo, el Hotel Francés de Maury, y sobretodo al nacionalismo gastrónomico contrario a nuevas modas y hábitos importados.

El historiador infunde vida a la poesía satírica de los románticos Manuel Adolfo García (« Un hotel ») y Aureliano Villarán («El restaurant»). Revela cómo los « europeizados hoteles en creciente boga se habían limeñizado al igual que los cafés, fondas y otros negocios del ramo" (p. 213). El trabajo del doctor Holguín plantea hipótesis y abre nuevas pistas de investigación. Se tratará de seguirlas explorando y utilizando otras fuentes como la tardía Herencia de Clorinda Matto o el interesante testimonio de Adriana de González Prada. De esa forma, superando los tópicos sobre la Lima atrasada del XIX, creo que se llegará a configurar la complejidad de la historia cultural y social del Perú decimonónico.

\section{AUTORES}

\section{ISABELLE TAUZIN-CASTELLANOS}

Université Michel de Montaigne Bordeaux 3 